\title{
やまじ風の数值シミュレーション
}

\section{Numerical simulation of the Yamaji-kaze with a non-hydrostatic model}

\author{
斉藤 和 雄 ${ }^{*}$ \\ Kazuo SAITO
}

\begin{abstract}
A three-dimensional non-hydrostatic anelastic model using a radiative-nesting lateral boundary condition is applied to the simulation of the Yamaji-kaze on 27 September 1991 caused by the Typhoon 9119. A 2.5 $\mathrm{km}$-resolution model, which is double-nested with the operational forecast model of the Japan Meteorological Agency, successfully simulates the downslope wind and associated internal hydraulic jump in the lee of the Shikoku Mountains. The model-simulated wind reproduces well the time change of the observed wind, including the abrupt increase of the southerly wind (onset of the Yamaji-kaze).
\end{abstract}

\section{Introduction}

The Yamaji-kaze is a well-known local wind in Japan. It is a strong downslope wind which occurs over the northern coastal plain of Shikoku when the low-level synoptic wind is southerly. As shown in previous studies (Saito and Ikawa 1991; Saito, 1993), the Yamaji-kaze is a nonlinear large amplitude mountain wave accompanied by an internal hydraulic jump, which has several characteristic features such as the Yamaji-kaze front (a line of discontinuity along which the surface wind direction suddenly changes) and the Domai (a northerly wind on the north side of the Yamaji-kaze front).

In the previous studies, we conducted two-dimensional (Saito and Ikawa, 1991) and three-dimensional (Saito, 1993) simulations of the Yamaji-kaze on 21 April 1987. Although these experiments presented numerical verification of mechanism of the Yamaji-kaze and basically succeeded in reproducing the characteristic wind field of an actual Yamajikaze, the simulations were artificial in that simple boundary conditions were used.

In this study, we modify the three-dimensional nonhydrostatic model used in Saito (1993) so that it can represent the time changing environmental field with one-way nesting. The operational forecast model (Japan Spectral Model; henceforth JSM) of Japan Meteorological Agency provides the lateral boundary condition for the non-hydrostatic model. The double nesting procedure enables us to conduct a simulation with $2.5 \mathrm{~km}$ horizontal resolution. The model is applied to the simulation of the Yamaji-kaze of 27 September 1991, which caused unprecedented wind damage to electric supply networks in Shikoku.

\section{The Yamaji-kaze of 27 September 1991}

On 27 September 1991, a strong typhoon (T9119, Mireille) hit Western Japan and caused extensive wind damages. In Shikoku, twelve transmission towers of the Shikoku Electric Power Company unprecedentedly collapsed by a strong local wind associated with the Yamaji-kaze.

Figure 1 shows the track of T9119. In the early stage, the typhoon moved northwestward in the Philippine Sea slowly, then it turned northeastward on 26 September, and reached northern Kyushu at 16 JST, 27 September. When T9119 landed, the central pressure was $940 \mathrm{hPa}$ and the storm area extended to $440 \mathrm{~km}$ from the center. In western Japan, maximum instantaneous winds greater than $50 \mathrm{~m} / \mathrm{s}$ were

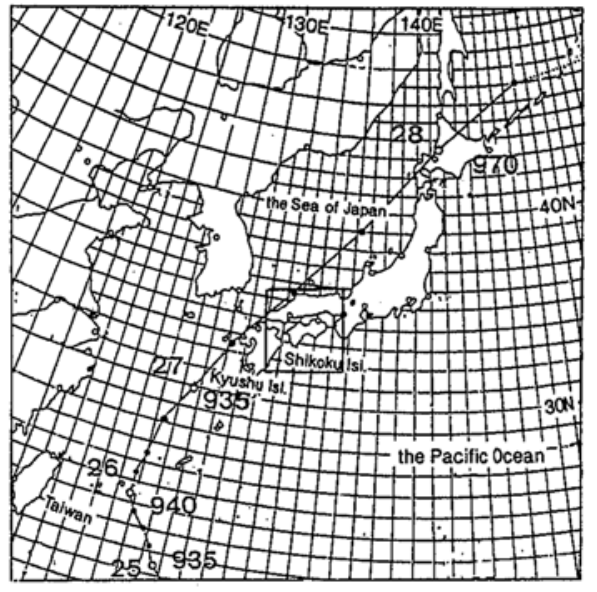

Fig.1. The track of T9119. Open circles show the locations of the typhoon at every 09 JST. Numerals on the right show the central pressure $(\mathrm{hPa})$ of the typhoon at the time. Solid circles show the locations of the typhoon at every 6 hours.

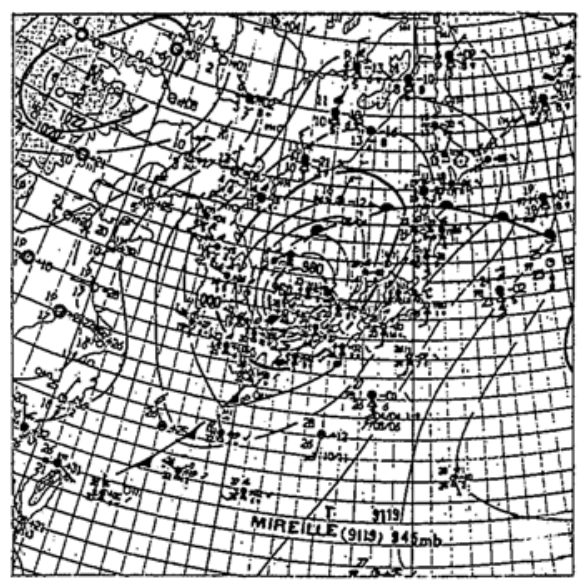

Fig. 2. The surface synoptic weather charts for 21 JST 27 September 1991.

\footnotetext{
*気象研究所予報研究部、主任研究官

Senior Researcher, Meteorological Research Institute
} 


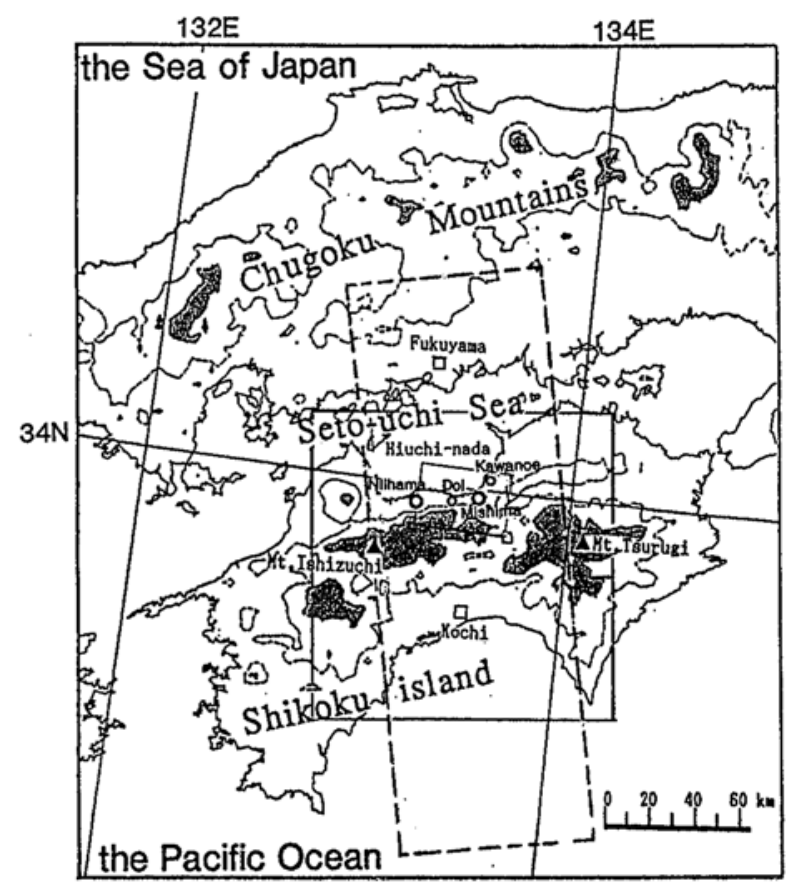

Fig. 3. Geographical map of Shikoku. The contour interval of elevation is $400 \mathrm{~m}$, with areas above $800 \mathrm{~m}$ height shaded. The square framed by the thick solid line shows the model domain of the $2.5 \mathrm{~km}-\mathrm{NHM}$. The rectangle framed by the broken line shows the model domain used in Saito (1993). The small rectangle indicated by the thin line represents the Yamaji-kaze region shown in Fig. 4.

observed at several local meteorological observatories along the track of the typhoon, but in Shikoku, about 200-300 km distant from the typhoon center, none of the staffed meteorological observatories recorded maximum instantaneous winds greater than $40 \mathrm{~m} / \mathrm{s}$. The surface weather charts for 21 JST (local time, = 12 UTC) 27 September is shown in Fig. 2.

Figure 3 shows a geographical map of Shikoku. The Yamaji-kaze occurs over the northern slope of the central part of the Shikoku Mountains and the northern coastal plain from Niihama to Kawanoe facing Hiuchi-nada when the synoptic wind is southerly.

Figure 4 shows the topography in the region where the Yamaji-kaze occurs. A main transmission network of the Shikoku Electric Power Company, which had been set up along an offset of the Shikoku Mountains (the Ho-oh Mountains), was severely damaged by the strong wind of T9119.

Figure 5 displays the anemometer trace taken at one of the collapsed transmission towers. Instantaneous wind speeds grater than $65 \mathrm{~m} / \mathrm{s}$ were recorded from $1830 \mathrm{JST}$ to $1915 \mathrm{JST}$, just before the collapse. The storm was accompanied by weak intermittent rain, but the general intensity was less than 2 $\mathrm{mm} / \mathrm{h}$ in the Yamaji-kaze region.

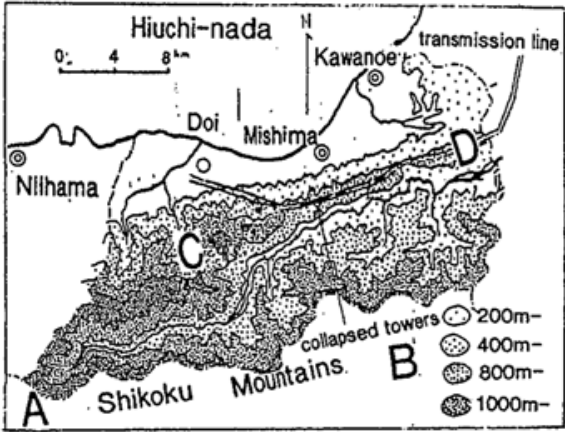

Fig. 4. Topography in the region where the Yamaji-kaze occurs. The main mountain range of the Shikoku Mountains runs from A to B while an offset (the Hooh Mountains) runs from $C$ to $D$. Double lines show the transmission line of the main electric supply network of the Shikoku Electric Power Company. The location where the transmission towers collapsed is shaded.

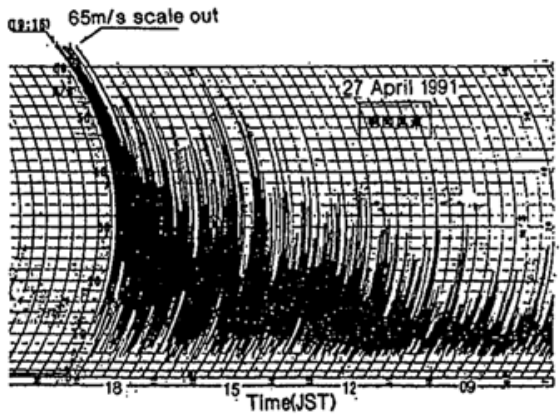

Fig. 5. Anemometer trace recorded at a transmission towers collapsed by the Yamaji-kaze. Time runs from right to left. The anemometer was installed at $27.5 \mathrm{~m}$ height from ground level.

\section{Numerical Model}

The dynamical framework of the numerical model is based on the anelastic version of the nonhydrostatic model developed at the Forecast Research Department of the Meteorological Research Institute (Ikawa and Saito, 1991), while the model has been extensively improved so that it can be nested with an other coarse-mesh model.

Initial values for the nonhydrostatic model is prepared by interpolating the prognostic variables such as wind, potential temperature and specific humidity predicted by the outer coarse mesh model. We modify the interpolated wind field by variational calculus in order to obtain three-dimensional massconsistent wind field which satisfies the continuity equation and the upper and lower boundary conditions. For the lateral boundary, radiative nesting boundary conditions are employed, while the detail of the nesting procedure is given in Saito and Ikawa (1992) and Saito (1994).

To determine the diffusion coefficients, turbulent closure model is employed. Resistance law calculates surface momentum and heat fluxes according to distribution and temperature of sea and land. The model incorporates explicit cloud representation, but it is switched off in the the simulation. 
In the simulation, the Japan Spectral Model (JSM) with 40 $\mathrm{km}$ horizontal resolution serves as the outer coarse-mesh model which supplies the nonhydrostatic model the initial values and boundary values. JSM is 19-level limited-area model which had been used as the operational forecast model of JMA from March 1988 to February 1992.

Figure 6 shows the nesting relations between the numerical models. For the first nesting procedure, a $10 \mathrm{~km}$ resolution version of the nonhydrostatic model (10 km-NHM), whose horizontal domain covers $500 \mathrm{~km} \times 500 \mathrm{~km}$ (square in Fig.1), is nested with JSM using 6 hours forecast of JSM as the initial values. For the second nesting procedure, a $2.5 \mathrm{~km}$ resolution version of the nonhydrostatic model (2.5 km-NHM), whose domain covers $125 \mathrm{~km} \times 125 \mathrm{~km}$ (square in Fig.3), is nested with the $10 \mathrm{~km}-\mathrm{NHM}$ using its 3 hours forecast as the initial values. The two NHMs have the identical vertical grid structure containing 30 levels with variable grid intervals $(\Delta z=$ $40 \mathrm{~m}-1160 \mathrm{~m})$.

\section{Results}

Figures $7 \mathrm{a}$ and $7 \mathrm{~b}$ show the 18 hours forecast of the lowestlevel wind by the $10 \mathrm{~km}-\mathrm{NHM}$ and observed surface wind at the time (21 JST 27 September). The observed large-scale flow pattern is reproduced by the model, but conspicuous downslope wind is not simulated over the northern coastal plain of Shikoku. In Fig. 7b, the surface wind over Shikoku has already changed to southwesterly, but the simulated winds in Fig. 7a are still southerly. This discrepancy is attributable to the delay of the movement of T9119 predicted by JSM.

Figure 8a shows the 15 hours forecast of the lowest-level wind by the $2.5-\mathrm{km}$ model. A strong wind area greater than 20 $\mathrm{m} / \mathrm{s}$ is seen over the eastem part of the coastal plain near Doi and Mishima. The Yamaji-kaze front is located over the southeastern part of the Hiuchi-nada. Figures $8 \mathrm{~b}$ show the vertical cross-sections of horizontal wind through the central part of the Shikoku Mountains ( $y z$-plane of $x=66.25 \mathrm{~km}$ in Fig. $8 \mathrm{a})$. A strong wind area greater than $50 \mathrm{~m} / \mathrm{s}$ is seen in the lee of the Ho-oh Mountains, nearly corresponding to the location where the transmission towers collapsed.

Figure 9 shows the time sequence of the observed surface winds at Niihama and Mishima, and the simulated lowest-level wind by JSM, the $10 \mathrm{~km}-\mathrm{NHM}$, and the $2.5 \mathrm{~km}-\mathrm{NHM}$ at the grid points in the vicinity of Niihama and Mishima. At Niihama, in the western part of the coastal plain, the wind was northeasterly until $15 \mathrm{JST}$, and then the strong southerly wind began at 16 JST, corresponding to the onset of the Yamajikaze. Neither JSM nor the $10 \mathrm{~km}-\mathrm{NHM}$ simulate the northerly wind before the onset of the Yamaji-kaze. The $2.5 \mathrm{~km}-\mathrm{NHM}$ simulates the northerly wind as well as the onset of the Yamaji-kaze. At Mishima, in the eastern part of the coastal plain and near the lee of the col of the Shikoku Mountains, the main wind directions were east or southeasterly during the simulation period. The southerly wind explosively increased after $19 \mathrm{JST}$, and no wind was obtained owing to the failure of the power supply. JSM does not simulate the downslope wind. In the $10 \mathrm{~km}-\mathrm{NHM}$, the simulated winds are too strong from the beginning. The $2.5 \mathrm{~km}-\mathrm{NHM}$ simulates fairly well the explosive increase of the southerly wind.

Figure 10a shows the time change of the wind speed observed at one of the destroyed transmission towers which was set up on the ridge of the Ho-oh Mountains (the same one as that of Fig. 5). The anemometer was installed at $27.5 \mathrm{~m}$

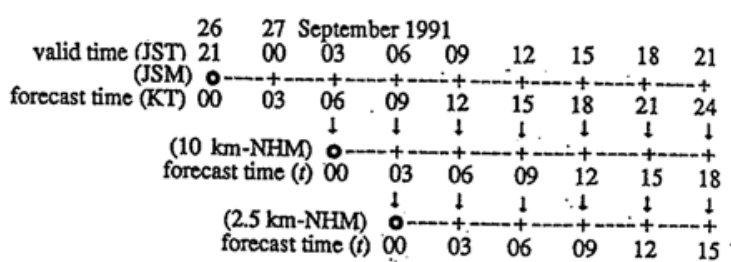

Fig. 6. The nesting relations between the numerical models.
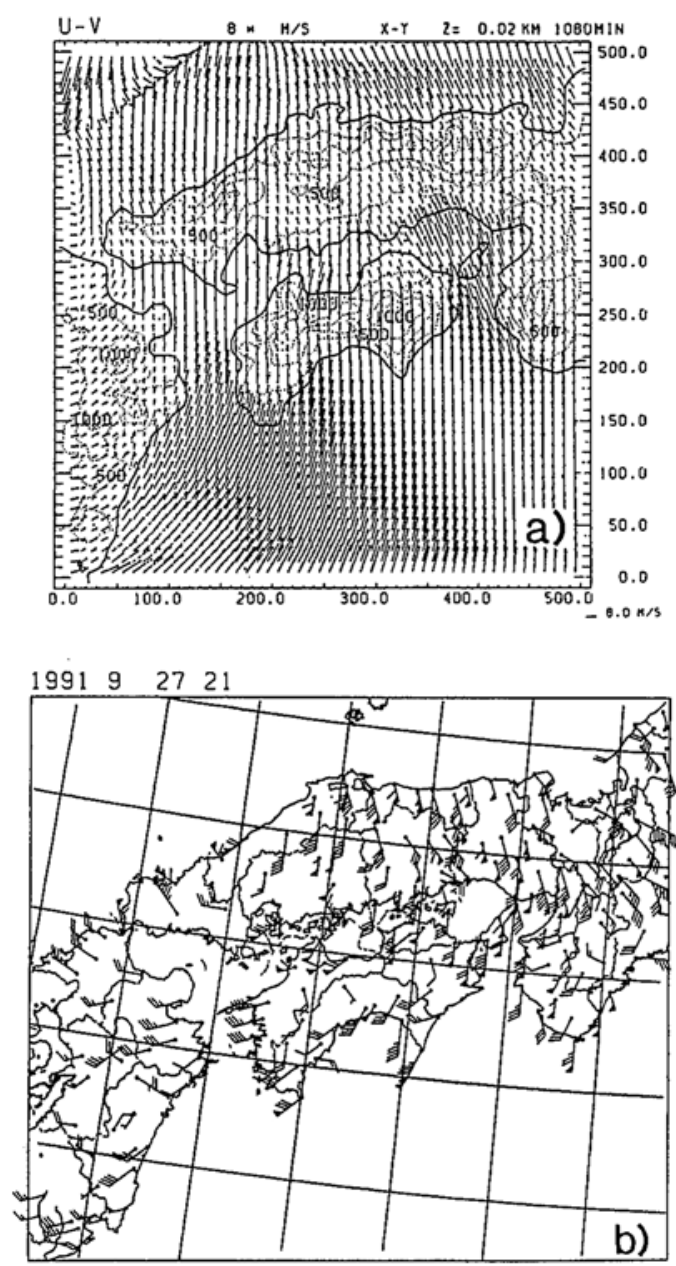

Fig. 7. a) The 18 hours forecast of the lowest level ( $20 \mathrm{~m}$ above the surface) wind of the $10 \mathrm{~km}$ NHM. The lower-right arrow indicates the scale of $8 \mathrm{~m} / \mathrm{s}$. The contours show the height of the orography of the $10 \mathrm{~km}-\mathrm{NHM}$ ( $250 \mathrm{~m}$ interval).

b) The observed surface wind at $21 \mathrm{JST}, 27$ September 1991. The short barbs on an arrow indicate $1 \mathrm{~m} / \mathrm{s}$, and long barbs indicate $2 \mathrm{~m} / \mathrm{s}$. 

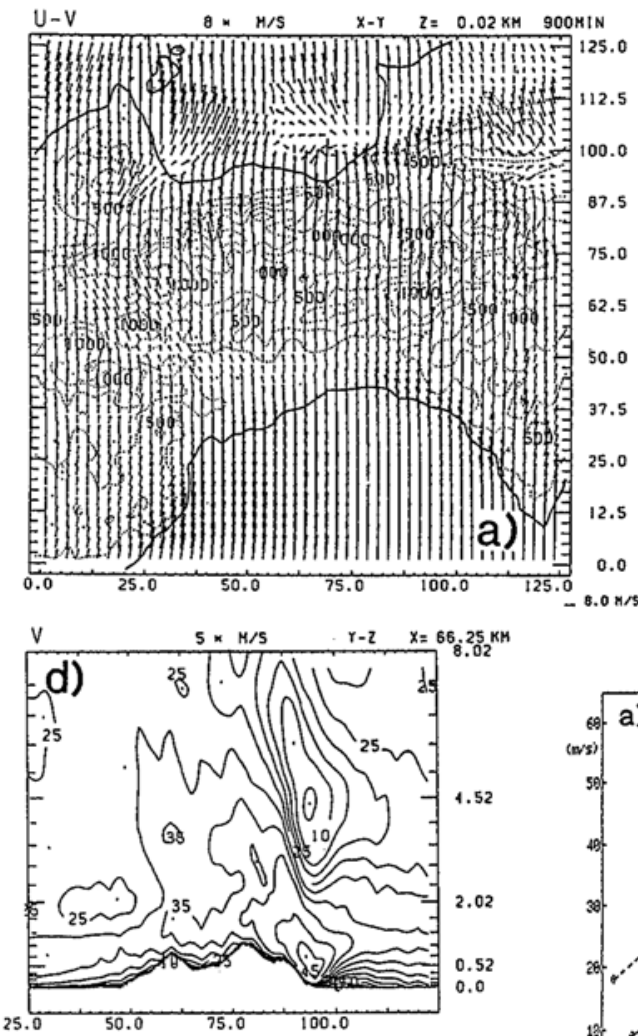

Fig. 8. The 15 hours forecast of the $2.5 \mathrm{~km}-\mathrm{NHM}$. a) The lowest level ( $20 \mathrm{~m}$ above the surface) wind. The lower-right arrow indicates the scale of $8 \mathrm{~m} / \mathrm{s}$. The contours show the height of the orography of the $2.5 \mathrm{~km}-\mathrm{NHM}$ ( $250 \mathrm{~m}$ interval) b) The vertical cross-section of the $y$-component of the wind through the $y z$-plane of $x=66.25 \mathrm{~km}$ The contour interval is $5 \mathrm{~m} / \mathrm{s}$.

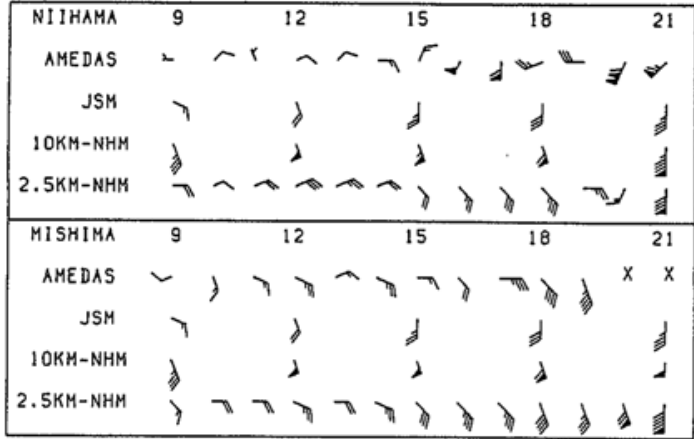

Fig. 9. Upper: The time sequence of the observed surface wind at Niihama (AMEDAS) and the simulated lowest wind by JSM, $10 \mathrm{~km}-\mathrm{NHM}$, and $2.5 \mathrm{~km}$ NHM at the point in the vicinity of Niihama.

Lower: As in a) except for Mishima. No wind was observed after 19 JST owing to the failure of power supply.
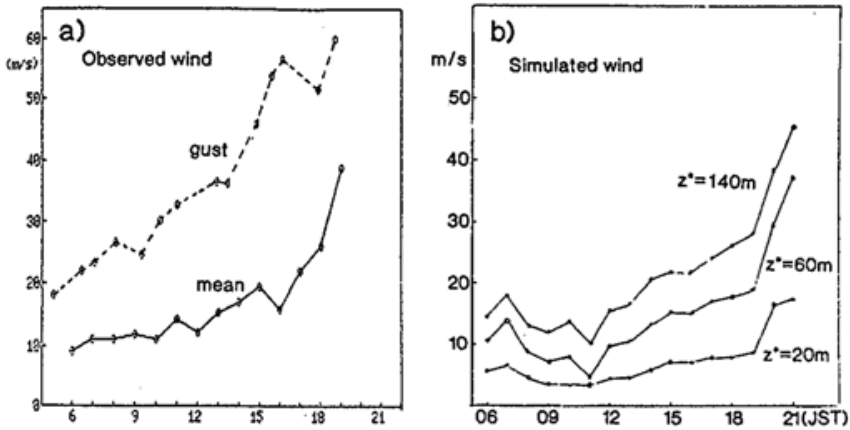

Fig. 10 a) The time change of the wind speed observed at one of the collapsed transmission towers. Broken line shows the gusts, while solid line shows the mean wind. No wind was observed after 1915 JST.

b) The time change of the model simulated wind speed with the $2.5 \mathrm{~km}-\mathrm{NHM}$ at the point $(x, y)=$ $(66.25 \mathrm{~km}, 90.0 \mathrm{~km})$.

height from the ground level. The broken line shows the gusts, while the solid line shows the mean wind. Figure 10b shows the time change of the simulated wind speed by the $2.5 \mathrm{~km}$ NHM at the grid point near the transmission tower. The time change of the second-level wind, $60 \mathrm{~m}$ above the ground surface, corresponds well to the time change of the observed mean wind except about one hour delay, which is probably attributable to the delay of the forecast of the typhoon by JSM.

\section{Acknowledgment}

The author expresses his heartfelt thanks to the late Dr. Motohki Ikawa for his valuable comments to modify the nonhydrostatic model. Thanks are extended to Drs. Fumiaki Fujibe and Makiko Kato and Mr. Kazumasa Aonashi of MRI, and Dr. Masashi Nagata of JMA for their helpful suggestions. The wind data taken at the transmission tower was provided by courtesy of the Shikoku Electric Power Company. The basic versions of JSM was provided by the Numerical Prediction Division of JMA.

\section{References}

Ikawa M. and K. Saito, 1991: Description of a nonhydrostatic model developed at the Forecast Research Department of the MRI. Technical Reports of the MRI, 28, 238pp.

Saito, K. and M. Ikawa, 1991: A numerical study of the local downslope wind "Yamaji-kaze" in Japan. J. Meteor. Soc. Japan, 69, 31-56.

Saito, K. and M. Ikawa, 1992: Numerical simulation of local wind by a nonhydrostatic nested model. Tenki, 39, 615-625 (in Japanese).

Saito, K., 1993: A numerical study of the local downslope wind "Yamaji-kaze" in Japan. Part 2: -Nonlinear aspects of the 3D flow over a mountain range with a col-. J. Meteor. Soc. Japan 71, 247-271.

Saito, K., 1994: A numerical study of the local downslope wind "Yamaji-kaze" in Japan. Part 3: Numerical simulation of the 27 September 1991 windstorm with a non-hydrostatic multinested model. J. Meteor. Soc. Japan (in press). 